\title{
"It's different for girls": gender differences in the friendships and conflict of autistic and neurotypical adolescents
}

Keywords: autism, girls, gender, friends, relationships, peers, conflict

Word count: 7,060 (excluding tables and references) 


\begin{abstract}
This mixed-methods study examined gender differences in the friendships and conflict experiences of autistic girls and boys relative to their neurotypical peers. One hundred and two adolescents (27 autistic girls, 26 autistic boys, 26 neurotypical girls, 23 neurotypical boys), aged between 11 and 18 years completed the Friendship Qualities Scale (FQS), the Revised Peer Experiences Questionnaire (RPEQ) and were interviewed about their friendships. Results demonstrated that in many ways, the friendships and social experiences of autistic girls are similar to those of neurotypical girls. Autistic girls, however, have significantly more social challenges than their neurotypical peers, experiencing more conflict, and finding that conflict harder to manage successfully. Autistic boys showed quantitatively different friendship patterns to all other groups. There were consistent gender differences in the type of conflict which boys and girls experienced, regardless of diagnostic status. These finding suggest that gender, rather than diagnosis per se, plays a critical role in the way that autistic adolescents perceive and experience their social relationships.
\end{abstract}


Friendships are crucial to our development as social individuals. They allow us to develop social skills (Cutting \& Dunn, 2006; Dunn, 1988; Dunn \& Cutting, 1999) and provide critical social and emotional support (Demir \& Urberg, 2004; Dumont \& Provost, 1999). Friendships can make us happier and healthier (Antonucci \& Akiyama, 1987; Berkman \& Syme, 1979), and their absence can lead to adjustment problems (Bowker et al., 2006).

There is a long-standing assumption that autistic people (see Kenny et al., 2016, and Sinclair, 1999, for discussion on terminology) do not want friends, are not socially motivated, and struggle with friendships (Chevallier et al., 2012), as social difficulties are a hallmark of autism (American Psychiatric Association, 2013). Yet many autistic young people have friends (Bauminger et al., 2008; Calder, Hill, \& Pellicano, 2013; Sedgewick et al., 2016), are involved in school networks (Kasari, Locke, Gulsrud, \& Rotheram-Fuller, 2011), and want to interact with peers (Travis, Sigman, \& Ruskin, 2001). Although a recent review of research into autistic children's friendships (Mean ages between 10.34 and 13.94 years) found they had fewer friends than neurotypical children, autistic children were highly satisfied with their friendships (Petrina, Carter, \& Stephenson, 2014). Friendships with non-autistic children ('mixed friendships') build better social and linguistic skills (Bauminger et al., 2007), and may be of higher 'quality' than non-mixed friendships (Bauminger et al., 2008).

Most studies included in Petrina et al.’s (2014) review involved cognitively-able children, meaning we know little about how friendships develop into adolescence. Their review also focused predominantly on friendships of autistic boys ( $86-92 \%$ male participants across studies), highlighting that little is known about autistic girl's friendships. This gender imbalance is unsurprising given the preponderance of males diagnosed with autism (Banach et al., 2012; Loomes, Hull, \& Mandy, 2017). Yet, it is problematic for our understanding of friendship in autism, given that neurotypical gender differences in friendship are well established (Aukett, Ritchie \& Mill, 1988; Caldwell \& Peplau, 1982). 
Girls reach more complex social and linguistic stages earlier than boys, allowing them to form relationships based on co-operative play and conversation (Barbu, Cabanes, \& Le Maner-Idrissi, 2011). In adulthood, women have friendships based on emotional sharing, whereas men focus on shared activities (Aukett, Ritchie, \& Mill, 1988). Female friendships tend to be more supportive than male friendships (DeGoede, Branje, \& Meeus, 2009). These factors may result in gendered expectations of how to be a friend - including for autistic boys and girls. On this basis, one might expect autistic girls' friendship experiences to be qualitatively more like those of non-autistic girls than autistic and non-autistic boys.

Although some theoretical (Baron-Cohen, 2002) and empirical work (e.g., BaronCohen \& Wheelwright, 2003; Head, McGillivray, \& Stokes, 2014) suggest that autistic females should have relationships more like those of males than neurotypical females, closer examination of adolescent friendships has revealed qualitative differences between cognitively-able autistic girls and boys. First, autistic boys and girls socialise in distinct ways. Kuo et al. (2013) found that autistic boys tended to play with friends, whereas autistic girls mostly talked with theirs, despite similar amounts of socialising overall. These skills may allow autistic girls to maintain closer and more empathetic friendships - and, ultimately, to interact as neurotypical girls expect. Second, although some research has highlighted that autistic girls have difficulties socialising with neurotypical girls (Cridland, Jones, Caputi, \& Magee, 2014), these challenges do not prevent them from forming friendships altogether (Vine Foggo \& Webster, 2017). Indeed, several studies have shown that many cognitivelyable autistic people - particularly girls and women (Hull et al., 2017; Lai et al., 2017) appear to develop compensatory strategies to 'camouflage' their social difficulties, helping them to be more socially included, even if they then struggle to maintain these relationships (Dean, Harwood, \& Kasari, 2017; Rynkiewicz et al., 2016). Third, autistic girls rate their 
best-friendships (as indexed by the Friendship Qualities Scale (FQS)) as more like those of non-autistic girls than autistic (and non-autistic) boys (Sedgewick et al., 2016).

These distinctions between autistic males and females appear to extend into adulthood. Although some women report social difficulties (Bargiela, Steward, \& Mandy, 2016; Hayward, McVilly, \& Stokes, 2016), many autistic women identify supportive relationships as key to being successful (Webster \& Garvis, 2016). Indeed, $80 \%$ of autistic women in one study reported being satisfied with their social lives (Baldwin \& Costley, 2015), even if they had also experienced social difficulties.

Together, these findings raise two key issues. The first is that the apparent qualitative differences in the social relationships of autistic males and females might be one reason why girls tend to be clinically identified later than their male counterparts (Begeer et al. 2012; Giarelli et al. 2010) or why they might miss out on a diagnosis altogether (Dworzynski et al. 2012; Russell et al. 2011). The second - most relevant to the current study - is that the friendship experiences of autistic girls/women appear to be more similar to those of nonautistic girls/women than autistic boys/men; that is, gender might be more central in determining social experiences than diagnostic status. Few of the abovementioned studies, however, directly compared (non-)autistic girls/women to (non-)autistic, which necessarily limits the sorts of conclusions that can be drawn. The current study sought to address this issue directly.

\section{Conflict within friendships}

We also sought to examine the degree and nature of conflict within autistic and nonautistic adolescents' friendships. Conflict is an inevitable part of relationships, and conflict management is a key skill. Among adolescents, bullying is the most common conflict, and is known to affect autistic children at higher levels than other children (Humphrey \& Hebron, 2014; Rowley et al., 2012). There is, by contrast, no work on conflict within the friendships 
of autistic adolescents. This 'relational aggression' is typically associated with girls, towards friends and female peers (Crick \& Grotpeter, 1995). It includes verbal behaviours such as gossiping, and non-verbal behaviours such as giving someone the 'silent treatment', 'staring daggers' (Shute, Owens, \& Slee, 2002), or eye-rolling to intimate dismissal (Underwood, 2004). These behaviours have similar negative outcomes to overt bullying, such as being hit or threatened (Baldry, 2004; Ortega et al., 2009).

It is possible that autistic girls most often experience this conflict when interacting with neurotypical girls who employ these methods (Bowie, 2007). This conflict is likely to be difficult for autistic girls to understand. Usually, the aggression takes place within the context of a 'friendship', requiring girls to develop a flexible understanding of 'friends', rather than taking people at face value (which autistic people can tend to do; e.g., Steward, 2013). Initial findings support this possibility. Sedgewick et al. (2016) found that while autistic adolescents reported similar degrees of conflict in their best-friendships, girls experienced more conflict in their wider friendships. Furthermore, autistic girls discussed similar relational conflict incidents to non-autistic girls, but autistic girls noted considerable difficulties managing them. Sedgewick et al.'s (2016) study, however, was limited to girls educated within special schools. These girls often have more pronounced autistic characteristics and additional cooccurring difficulties, and also have peers with other special educational needs, making their friendships experience potentially quite unlike autistic girls in mainstream placements.

\section{The Current Study}

Gendered patterns of friendships and conflict experiences are evident in neurotypical adolescents, suggesting that the social 'worlds' of boys and girls are qualitatively different. Here, we investigated whether the social experiences of autistic boys and girls also differ, and in similar ways to neurotypical adolescents. Specifically, we sought to (1) understand the nature of autistic adolescents' friendships in comparison to their neurotypical peers, including 
their experiences of conflict and, critically, (2) determine whether these friendship and conflict experiences differ by gender within diagnostic group.

To address these aims, we used a concurrent mixed-methods design, where one overarching question was simultaneously addressed by both quantitative and qualitative data (Creswell, 2002), to enable a holistic and contextual portrayal of the friendships and conflict experience of autistic adolescents. We administered questionnaires addressing best-friendship quality (Friendship Qualities Scale (FQS); Bukowski et al., 1994) and overt and relational conflict (Revised Peer Experiences Questionnaire (RPEQ); Prinstein, Boergers, \& Vernberg, 2001). Given initial work showing that the friendship experiences of autistic girls are more like those of neurotypical girls than autistic or neurotypical boys (Sedgewick et al., 2016), we expected girls to rate their best-friendships as stronger than boys, regardless of diagnostic status. We also predicted that autistic adolescents would experience more conflict than their neurotypical peers, particularly as victims (Schroeder et al., 2014). Nevertheless, we expected that we would see similar gendered patterns of conflict in both groups (Crick \& Grotpeter, 1995), with girls experiencing more relational conflict and boys experiencing more overt conflict; that is, the absence of an interaction between gender and diagnostic status.

To examine these issues in greater detail, and to elicit young peoples' views on their experiences, we also conducted semi-structured interviews with adolescents about their friendships, their social difficulties, and, critically, how these impacted their everyday lives.

\section{Method}

Participants. One-hundred-and-two adolescents (27 autistic girls, 26 autistic boys, 26 neurotypical girls, 23 neurotypical boys), aged between 11 and 18, were recruited through community contacts (see Table 1). All attended mainstream education currently ( $\mathrm{n}=94)$ or within the past two years $(n=8)$. Of those latter eight participants, three had moved from mainstream to special school on transition to high school, and five had transitioned during 
high school. There were no significant group differences in ethnicity, $\chi^{2}(1)=16.59, p=.28$, with $71 \%$ being from a White ethnic background, and $9 \%$ and $20 \%$ from Black and Asian backgrounds, respectively, which is more diverse than the UK population nationally (ONS Census, 2011).

All participants obtained Full-Scale IQ scores $>70$ on the Wechsler Abbreviated Scales of Intelligence-2 $2^{\text {nd }}$ edition (WASI-2; Wechsler, 2011), and were thus considered cognitively-able. Autistic and neurotypical participants were matched on age and intellectual ability. ANOVAs on adolescents' age, Full-Scale IQ, Performance IQ and Verbal IQ scores revealed no significant effects of group (autistic, neurotypical; $p s>.15$ ) or gender (male, female; $p s>.44)$, and no group x gender interactions ( $p s>.14)$.

insert Table 1 about here

All autistic participants had received an independent clinical diagnosis of an autism spectrum condition according to DSM (APA, 2000, 2013) or ICD-10 (WHO, 1993) criteria. Autistic participants completed Module $3(n=10)$ or Module $4(n=41)$ of the Autism Diagnostic Observation Schedule $-2^{\text {nd }}$ Edition (ADOS-2; Lord et al., 2012). Algorithm scores were converted to standardised ADOS severity scores (maximum score=10; Hus, Gotham, \& Lord, 2014; Lord et al., 2012). Autistic boys (M=5.45, SD=1.90) obtained significantly higher ADOS-2 severity scores than autistic girls $(\mathrm{M}=3.87, \mathrm{SD}=1.89)$, $t(36)=2.51, p=.01, d=.84$.

Two boys and four girls failed to meet the ADOS-2 threshold (score=7) for autism. Two girls also declined to take part in the ADOS-2. We retained these young people in analyses, however, given that they (i) had a pre-existing clinical diagnosis, (ii) had a statement of Special Educational Needs or Education, Health and Care plan, specifying 
autism as their primary need, and (iii) met threshold for autism on the parent-report Social Responsiveness Scale-2 ${ }^{\text {nd }}$ edition (SRS-2: Constantino \& Gruber, 2012) (see Table 1). Also, removal of these participants from analyses did not change the pattern of results.

\section{Measures}

\section{Social Responsiveness Scale - $2^{\text {nd }}$ edition (SRS-2: Constantino \& Gruber, 2012).}

Parents completed the SRS-2 School-Age Form (Constantino \& Gruber, 2012), a 65-item questionnaire assessing social and behavioural difficulties associated with autism.

Participants rate statements about behaviours over the last six months on a scale ranging from 1 (not true) to 4 (almost always true). Higher scores reflect greater severity of autistic symptoms. In the current sample, reliability was excellent (autistic: Cronbach's $\alpha=.91$; neurotypical: $\alpha=.88$ ).

Friendship Qualities Scale (FQS: Bukowski et al., 1994). The FQS assesses adolescents' perceptions of their best-friendship. It has 23 items, rated on a 5-point scale ranging from 1 (not true at all) to 5 (very true). It covers five components of friendship: Companionship (e.g., 'My friend and I do things together'); Conflict (e.g., 'My friend and I can argue a lot'); Help (e.g., 'My friend would help me if I needed it'); Security (e.g., 'If I say sorry after a fight or an argument, everything will be alright'); and Closeness (e.g., 'If my friend had to move away I would miss him/her').

The measure showed excellent reliability (autistic: $\alpha=.92$; neurotypical: $\alpha=.91$ ). The four positive subscales (Companionship, Closeness, Help, Security) were also highly intercorrelated $(r s=.55-.72)$, although the Conflict subscale was not significantly correlated with any other subscale $(r s<.06)$. To reduce the number of dependent variables in analyses, we created a novel, robust composite 'Friendship Strength' score by averaging the four positive subscales, and analysed the Conflict subscale separately. Higher scores indicate greater friendship strength/conflict. 
Revised Peer Experiences Questionnaire (RPEQ) (Prinstein et al., 2001). The

RPEQ is an 18-item questionnaire assessing the frequency of overt (e.g., 'Someone threatened to hurt or beat me up') and relational (e.g., 'I left someone out') bullying behaviours that a participant both engages in and is subject to. Items are rated on a 5-point scale ranging from 0 (never) to 4 (a few times a week). It has aggressor (e.g., I chased someone like I was really trying to hurt them') and victim (e.g., 'Someone chased me like they were really trying to hurt me') versions. The scale yields eight subscales (Victimhood, Aggression, Overt, Relational, Overt Victimhood, Relational Victimhood, Overt Aggression, Relational Aggression) and an overall Total score (created by summing all subscale scores). Good internal consistency ( $\alpha=.76-.80)$ has been reported in neurotypical populations (McLaughlin, Hatzenbuehler, Mennin, \& Nolen-Hoeksema, 2011; Siegel, La Greca, \& Harrison, 2009). Cronbach's $\alpha$ for Total scores in our sample was high (autistic: $\alpha=.87$; neurotypical: $\alpha=.88$ ). Higher scores reflect greater involvement in peer conflict.

Semi-structured interview. The semi-structured interview (see Appendix A) comprised two parts: (1) friendships and conflict, and (2) critical incident. Part 1 included open-ended questions about adolescents' friendship experiences. Questions were initially generated from the ADOS-2 'Friendships and Marriage' section (see Sedgewick et al., 2016), such as 'How do you know if someone is your friend?' Questions were added to probe specific age-appropriate issues, such as 'Do you see your friends outside school?'.

Part 2 focused on conflict in young people's relationships, using - for the first time with autistic adolescents - a critical incident technique (Flanagan, 1954). Participants identified two specific experiences with peers, one positive and one difficult, and asked to elaborate on them. This method was designed to elicit young people's conflict experiences in detail, including their cognitions and emotional responses. It also sought to examine how adolescents manage - or fail to manage - such conflict. 


\section{General Procedure}

All parents gave informed written consent for their children to take part and adolescents also provided assent. Participants were seen for 1-2 sessions, either at home, the University, or at school (depending on participant preference). The ADOS-2 was administered at the beginning of the session (if applicable), followed by the WASI-2, FQS, RPEQ and, once rapport was established, the interview. Parents completed questionnaires (general background, SRS-2) during the session or returned them by post.

\section{Data Analysis}

Data from questionnaires (SRS-2, FQS, RPEQ; see Tables 1-3) were analysed in turn using SPSS v. 22 (IBM Corp, 2013). Between-group ANOVAs with group (autistic, neurotypical) and gender (female, male) as factors were conducted on the total and sub-scale scores of each measure.

Interview recordings were transcribed verbatim and subjected to thematic analysis (Braun \& Clarke, 2006), including (1) data familiarisation, (2) generation of initial codes, (3) searching for themes, (4) reviewing themes, (5) defining and naming themes, and (6) report production (i.e., write-up of results). We adopted an inductive ('bottom-up') approach, providing descriptive overviews of the key features of the semantic content of data within an essentialist framework. The analytic process was therefore iterative in nature, in which the first author coded transcripts line-by-line after initial data familiarisation, and the two other authors read and independently coded $20 \%$ of the transcripts, blind to the first author's codes (to counter potential analytic biases). The authors then met several times to discuss their codes, identify discrepancies and reach consensus via discussion (in some cases, going beyond the original subset to ensure any amendments or additions were applied to the full dataset), and decide on the final themes and subthemes. 


\section{Results}

Social responsiveness. A 2 (group: autistic vs neurotypical) x 2 (gender: male, female) ANOVA on SRS-2 total scores (see Table 1) revealed a significant effect of group, $F(1,98)=491.80, p>.001, \eta_{\mathrm{p}}{ }^{2}=.83$, with autistic adolescents $(\mathrm{M}=78.42, \mathrm{SD}=8.77)$ having more autistic behaviours than neurotypical adolescents $(\mathrm{M}=46.65, \mathrm{SD}=5.81)$. There was a significant effect of gender, $F(1,98)=5.82, p=.02, \eta_{\mathrm{p}}{ }^{2}=.05$, and a significant group $\mathrm{x}$ gender interaction, $F(1,98)=1.55, p=.02, \eta_{\mathrm{p}}{ }^{2}=.01$. Planned t-tests showed, unexpectedly, that autistic girls' parents scored them significantly higher on the SRS-2 than all other groups $(p s<.01)$.

Best-friendship quality. All participants nominated a best friend, and all but two named a same-sex individual. A 2 (group: autistic vs neurotypical) x 2 (gender: boys vs girls) ANOVA on total friendship-strength scores (see Table 2) revealed significant effects of group, $F\left(1,98=15.38, p=.001, \eta_{\mathrm{p}}^{2}=.13\right.$, and gender, $F(1,98)=4.76, p=.03, \eta_{\mathrm{p}}{ }^{2}=.04$, with autistic adolescents $(\mathrm{M}=3.59, \mathrm{SD}=.76)$ rating their best-friendship as less strong than neurotypical adolescents $(\mathrm{M}=4.10, \mathrm{SD}=.52)$, and boys $(\mathrm{M}=3.68, \mathrm{SD}=.66)$ rating their bestfriendships as less strong than girls $(\mathrm{M}=3.97, \mathrm{SD}=0.71)$. There was no significant group $\mathrm{x}$ gender interaction, $F(1,98)<1$. Analysis of individual subscales demonstrated main effects of group (for Companionship, Helpfulness) and/or gender (for Closeness, Security, Helpfulness scores) but no significant group x gender interactions (all ps>.16).

insert Table 2 about here

For FQS Conflict subscale scores, there was a main effect of group, $F(1,98)=5.07$, $p=.02, \eta_{\mathrm{p}}{ }^{2}=.04$. Autistic adolescents $(\mathrm{M}=3.66, \mathrm{SD}=.87)$ had best-friendships characterised by more conflict than neurotypical adolescents $(\mathrm{M}=3.24, \mathrm{SD}=.99)$. Unlike friendship-strength 
scores, there was no main effect of gender, $F(1,98)=1.25, p=.27, \eta_{\mathrm{p}}{ }^{2}=.01$, or significant group x gender interaction, $F<1$.

Peer conflict. Table 3 shows the RPEQ subscale and total scores (accounting for victim/aggressor roles). As expected, for the Total involvement in conflict score, there was a significant effect of group, $F(1,98)=7.65, p=.007, \eta_{\mathrm{p}}^{2}=.07$, with autistic adolescents $(\mathrm{M}=11.89, \mathrm{SD}=8.01)$ experiencing more conflict than neurotypical peers $(\mathrm{M}=7.80, \mathrm{SD}=6.49)$. There was no significant effect of gender, $F<1$, but there was a significant group x gender interaction, $F(1,98)=5.33, p=.02, \eta_{\mathrm{p}}^{2}=.05$. Planned comparisons revealed that autistic girls $(\mathrm{M}=13.41, \mathrm{SD}=6.46)$ experienced significantly more conflict than both neurotypical girls $(\mathrm{M}=6.15, \mathrm{SD}=4.44), t(51)=3.65, p=.001, d=1.01$, and autistic and neurotypical boys $(p s<.05)$. Autistic boys experienced similar levels of conflict to neurotypical boys, $t(47)=.31, p=.75$, $d=.09$, but significantly more than neurotypical girls, $t(50)=2.70, p<.01, d=.75$, while there was no significant difference between neurotypical boys and girls, $t(47)=1.77, p=.06, d=.54$.

insert Table 3 about here

A similar pattern was found for overall Victimhood scores. There was a significant effect of group, $F(1,98)=11.53, p=.001, \eta_{\mathrm{p}}{ }^{2}=.10$, no significant main effect of gender, $F<1$, and a significant group $\mathrm{x}$ gender interaction, $F(1,98)=9.35, p=.003, \eta_{\mathrm{p}}{ }^{2}=.08$. This interaction was driven by autistic girls, who reported significantly higher Victimhood than all other groups $(p s<.05)$ (see Table 3). Autistic boys reported significantly higher Victimhood scores than neurotypical girls, $t(50)=2.63, p=.01, d=.73$, but not boys, $t(47)=.24, p=.81, d=.07$.

Perhaps unsurprisingly, all adolescents rarely reported being the aggressor. There were no significant effects of group ( $p s>.20)$ or gender ( $p s>.20)$, and no group x gender interactions $(p s>30)$ for both Total and Relational Aggressor scores. For Overt Aggression 
there were main effects of group, $F(1,98)=5.08, p=.03, \eta_{\mathrm{p}}{ }^{2}=.03$, and gender, $F(1,98)=6.63$, $p=.01, \eta_{\mathrm{p}}{ }^{2}=.05$, with autistic adolescents and boys being more overtly aggressive, but no group x gender interaction, $F<1$.

For Total Overt Conflict, there were significant effects of group, $F(1,98)=21.29$, $p>.01, \eta_{p}{ }^{2}=.09$, and gender, $F(1,98)=7.60, p>.01, \eta_{p}{ }^{2}=.03$, but no group $x$ gender interaction, $F(1,98=1.21, p=.27$. Boys $(\mathrm{M}=4.27, \mathrm{SD}=4.26)$ experienced more overt conflict than girls $(\mathrm{M}=2.36, \mathrm{SD}=3.98)$. Autistic adolescents $(\mathrm{M}=4.81, \mathrm{SD}=4.26)$ experienced more overt conflict than neurotypical adolescents $(\mathrm{M}=1.61, \mathrm{SD}=2.51)$.

Regarding Total Relational conflict scores, there were no significant effects of group, $F<1$, or gender, $F(1,98)=2.66, p=.11$, but there was a significant group $\mathrm{x}$ gender interaction, $F(1,98)=6.21, p=.01, \eta_{\mathrm{p}}{ }^{2}=.06$. Autistic girls reported experiencing greater relational conflict than all other groups $(p s<.03)$. A similar pattern was found for Relational Victimhood, with no main effect of group, $F(1,98)=1.51, p=.22$, but a significant main effect of gender, $F(1$, $98)=5.09, p=.02, \eta_{\mathrm{p}}{ }^{2}=.04$, and a significant group $\mathrm{x}$ gender interaction, $F(1,98)=8.42, p=.005$, $\eta_{p}{ }^{2}=0.07$. Autistic girls experienced significantly more Relational Victimhood than all other groups $(p s<.01)$. There were no significant group differences in Relational Victimhood between autistic boys and neurotypical boys and girls ( $p s>.26)$.

Semi-structured Interviews. Semi-structured interviews were conducted with 90 participants (27 autistic girls, 23 autistic boys, 20 neurotypical girls, 20 neurotypical boys) who consented to take part. Interviews varied in length (range $=4: 56-45: 25 \mathrm{~min}$ ), but mean times were similar across groups (range $=12.41-16.36 \mathrm{~min}$ ). We asked about two topics friendships and conflict. The themes identified from these discussions are presented below and in Figure 1. When attributing quotes, 'AB' refers to autistic boys, 'AG' to autistic girls, 'NB' to neurotypical boys and 'NG' to neurotypical girls. 
We identified three themes common to all young people, regardless of gender or diagnostic status. First, they described friends as people like me - of similar age and gender, with similar interests. Second, young people emphasised that friends are there for you, but the nature of this support differed by gender. Third, they discussed spending time together ("friends are people you could be with all the time", AG) with this contact strengthening relationships ("I think you become better friends if you spend time together", NB).

Despite these commonalities, there were also notable group differences, and gender rather than diagnostic status - was the differentiating factor: girls and boys had very different experiences. For this reason, and for the sake of brevity, thematic analyses are presented for each gender separately.

Girls. We identified nine themes in girls' responses (see Figure 1), grouped under the broader themes of 'nature of social networks', 'conflict experiences' and 'wanting to fit in'.

Nature of social networks. Having a few good friends was key, with all girls talking about having a small number of close friends that they considered to be "best" friends. These close friends were those who they spent the most time with and talked to most.

insert Figure 1 about here

Girls discussed the importance of these close friends for emotional and social support, that is, friends are people who are there for you. Both autistic and neurotypical girls emphasised that friends supported them. Emotional support could take the form of "being there for someone no matter what" (NG), which was important for negotiating adolescent 'drama'. Social support was key for autistic girls, with one saying "my friend helps me if I don't understand what the other girls mean" (AG). Friends often acted as mediators in an 
argument for both autistic and neurotypical girls - "people tell friends in the middle stuff so you can find out [why they are annoyed]" (AG).

While both groups had small numbers of close friends, a key difference between the groups was that neurotypical girls also had a wider group who were less close: "I have a best friend and close friends and then other friends who I hang around with" (NG). Most autistic girls instead described having one or two close friends, and seeing other people solely as classmates: "I tend to have one friend at a time really" (AG). For these girls, this was because friends are hard work, so maintaining more than one or two close relationships was difficult. These friendships were intense ("going to each other's houses every day", AG) and arguments within them could be devastating as "you have no-one else to go to" (AG).

Conflict. Arguing with friends was discussed by all girls, most commonly about gossip and changing group dynamics - "people saying things, gossip...then they have a massive falling out" (AG). Indeed, instances of relational conflict were discussed in detail, which, even if resolved, had a lasting impact on their friendships: “after that...I just don't feel as close to her" (NG); "I can count lists of people who were my friends" (AG).

While all girls experienced relational conflict, with strikingly similar causes and behaviours, autistic and neurotypical girls described different conflict resolution strategies. For major disagreements (as opposed to minor bickering), neurotypical girls described conflict resolution as a reciprocal process with joint problem-solving: "we decide to sit down and talk about it” (NG)'. In contrast, autistic girls described an 'all-or-nothing' approach, either taking sole responsibility for what had happened ("I would very quickly apologise to her", AG), or ending the friendship entirely, seeing the other person as the wrong-doer, ("I'm just like, "why did you lie?", AG), or feeling it could not be resolved (“we stopped being friends", AG). 
Wanting to fit in. Both autistic and neurotypical girls alluded to wanting to fit in, but in different ways. Neurotypical girls talked about dating to look cool: "they think it's just what you're meant to do" (NG). Few girls reporting having boyfriends, but most said people dated to fit in with the popular crowd. These behaviours could be seen as a form of 'camouflaging', as teenagers described seeking peer acceptance, even if they were not personally motivated to date. Equally, autistic girls talked about friends who "let you be yourself', implying that autistic girls feel they must frequently control how they appear, but can relax with true friends.

This desire to fit in could also lead to competition with friends - at least for neurotypical girls. Several neurotypical girls talked about competing with their friends, academically and socially ("you always want to be better...not just with grades but with friends and being cool online", NG). Autistic girls did not mention this competition, suggesting they were unaware of the dynamics between their neurotypical peers. One older girl (18 years), mentioned that she did not want to "drag [her friend] down by making her talk to someone who was not cool, like me" (AG). This was the only recognition by any autistic girl that there may be a social cost to their behaviours, or that their peers were evaluating them in a hierarchical way.

Online interactions on social media often served to reinforce offline friendships, making them both visible to others in their social networks ("I have it so I can like all the photos", AG) and more concrete. The number of 'likes' a photo got (positive reactions by friends or followers) was the key measure of how popular girls felt. They talked about the impact of online social obligations on real-life friendships ("you can like your friends stuff and make them look good", NG), and how not meeting these could result conflict ("we'll argue if someone's boyfriend likes someone else's picture", NG). 
Despite the closeness of their friendships, and general satisfaction, girls had high levels of friendship insecurity. Both autistic and neurotypical girls worried that they were in some way not good enough ('I'm worried if I don't deserve them, whether they are just putting up with me", NG). This anxiety could result in them withdrawing from friendships (“[I] just accepted that she'd give up on the friendship", AG). This insecurity played into conflict situations, with accusations of interfering in friendships: "they want you to be their friend more than someone else's...then the two of them argue" (NG).

To summarise, autistic and neurotypical girls were similar in many ways - how they defined their friendships, what they valued, and the conflict they experienced. There were also significant differences between the groups, however, with autistic girls having fewer, more intense friendships than neurotypical girls; being less socially competitive and aggressive; being more often the victims of relational aggression; and struggling more than their neurotypical peers in managing such conflict.

Boys. In contrast to girls, boys talked about activity-focussed, practical elements of friendship, and these patterns were common regardless of diagnostic status. We identified four themes (see Figure 1).

All boys talked about friends as people they do things with, rather than focussing on emotional closeness. These activities ranged from online gaming ("we made an actual chessboard out of blocks [in Minecraft]", AB) to sports ("we play football”, NB) but friendships were generally described as based on shared interests. Their friendship networks were different to those of girls, with boys having a larger number of less-close friendships, regardless of diagnostic status. Some boys explicitly framed friendships in contrast to those of girls ("we do stuff together, not just sit and talk like girls", AB), suggesting they saw conversation-based friendships as undesirable. This was particularly true for autistic boys, 
who spoke about choosing friends based on shared interests and proximity (being in the same class or living nearby).

The joking that went along with these shared activities was identified as the main cause of conflict for boys. Taking it too far was the common response when asked what boys and their friends argued about, saying "if we find something that annoys someone we just keep bringing it up" (NB), but this was generally described as being minor. A few autistic boys said they "never" argued with their friends. These boys were less interested in friendships in general, however, and so may simply not have been engaging with their peers enough to reach the point of irritation and conflict.

This practical approach to friendship was also visible in boys' discussions of conflict resolution. All boys talked about "just get[ting] on with it" (NB) when they argued with friends. They did not report any strong desire to talk over problems, possibly because the issues they were facing were very different to girls, such as "[someone] talking too much" $(\mathrm{AB})$ and said that "things just get resolved quite quickly" (NB). Boys also felt that disagreements had no lasting impact on their friendships and were easily fixed: "we just say 'sorry, we took it a bit far"” (AB).

Along with practical definitions of friendship, boys talked about what they meant by friends are there for you. Whereas girls focused on emotional and social support, boys concentrated on practical support. They knew someone was their friend if they were "backing you up" (NB). Autistic boys also talked about friends being people who do things for you, such as helping with homework: "a helpful person that helps with work" (AB).

This focus on what people $d o$ within friendship meant that autistic and neurotypical boys differed in the types of friendships they experienced, similar to autistic and neurotypical girls. Autistic boys said that friends were "people you play with" or "recognise", whereas neurotypical boys said that "they'd always listen to you". In contrast, neurotypical boys 
emphasised having a group of friends they chose to share time with, defined by factors such as shared humour and trust.

In sum, autistic and non-autistic adolescent boys reported their friendship and conflict experiences as highly similar - activity-focused, practically-supportive friendships combined with a laissez-faire attitude to conflict. The exception to this pattern was that neurotypical boys described more intimate friendship experiences than their autistic male counterparts.

Comparing girls and boys. There were many ways in which boys and girls were different - the numbers of friends they had, what they did with their friends, the types of conflict they experienced, and how they managed conflict when it occurred. One area where neurotypical girls and boys agreed, beyond the themes highlighted by all participants, was their approach to dating. Neurotypical girls reporting using dating to fit in, and neurotypical boys had similar attitudes: "they want to be popular". Many participants described their peers as dating "to be cool" (NB), or to "fit in with the popular lot" (NG), but it was not something that was especially important to them.

Autistic adolescents had a highly variable attitude to dating, from total disinterest - "I don't get it" $(\mathrm{AB})$ - to it being a top priority - "my friends and me, we're obsessed" (AG). This latter attitude was more the case for autistic girls than boys, with girls who had boyfriends describing them as their primary relationship - "my boyfriend...I'd say he's my best friend" (AG) - often because it was difficult to maintain multiple relationships.

\section{Discussion}

This study used mixed methods to examine gender differences in autistic and neurotypical adolescents' friendships and conflict experiences. Contrary to previous research (Rivet \& Matson, 2011; Van Wijngaarden-Cremers et al., 2013), our results revealed significant differences between autistic girls and boys, in line with neurotypical gendered patterns (Kuo et al., 2013). While autistic adolescents experienced more conflict in their best- 
and wider friendships than neurotypical peers, the type of conflict differed, with autistic girls reporting more relational conflict than all other groups - an unexpected and novel finding. Yet, perhaps the most important finding, identified from both the quantitative and qualitative data, was the gender-dependent differences autistic adolescents' friendship experiences. Autistic and non-autistic girls' conflict and friendships were more like each other than autistic and non-autistic boys, and vice versa. While there were some key exceptions to this pattern, these findings nevertheless provide compelling support for the possibility that gender may be more important than diagnosis in determining young autistic people's social experiences.

The nature of autistic friendships compared to neurotypical peers. Like previous studies (e.g., Bauminger \& Kasari, 2008; Calder et al., 2013; Sedgewick et al., 2016; see Petrina et al., for review), our autistic adolescents rated their best-friendship as less strong than that of neurotypical adolescents, having less companionship, and being less helpful. Autistic adolescents also experienced more conflict in their best-friendship than neurotypical adolescents, according to both quantitative and qualitative data. There were also similarities between autistic boys and girls, such as best-friendships that were less close than those of their neurotypical peers, experiencing more conflict with best-friends, and being subject to more overt conflict than their neurotypical peers.

Yet our analysis of the FQS also found significant differences between girls and boys, regardless of diagnosis. Girls rated their best-friendships as stronger, closer, more secure, and more helpful than boys, consistent with neurotypical friendship gender differences (Aukett, Ritchie, \& Mill, 1988). The absence of an interaction between group and gender suggested that autistic girls' best-friendships are in some key ways qualitatively more like those of neurotypical girls, than those of either autistic or neurotypical boys. These results speak 
against the notion that the friendships of autistic girls and women are quantitatively or qualitatively like those of autistic males, as posited by the EMB theory (Baron-Cohen, 2002).

This pattern of results converged with the findings from the semi-structured interviews, which clearly showed that autistic and neurotypical girls' social experiences, their opportunities and challenges, were similar regardless of diagnosis. Girls, autistic or not, had close friendships based around emotional sharing, talking, and time together, which would be expected given research on neurotypical female friendships (Aukett et al., 1988). Autistic girls, however, had fewer of these close friendships than neurotypical girls, tending to have one or two intense friendships because they found them more hard work. Maintaining these friendships was deeply important to them. This result directly contrasts with theoretical work suggesting that autistic people are fundamentally less socially motivated (Chevallier et al., 2012) and instead aligns with the conclusions presented by Lai et al. (2015), that autistic females have a greater "desire to interact with others" and have "one or few close friendships" (p. 13). Lai et al. further suggested that some of these differences may come from the different social expectations autistic girls face, creating a greater desire in girls to fit in through imitation (Kreiser \& White, 2014).

It is important to acknowledge that there were key differences between autistic and neurotypical girls, particularly around social challenges. While autistic girls rated their friendships similarly to neurotypical girls on the FQS, they described difficulties maintaining these relationships. Autistic girls also reported significantly more social challenges than neurotypical girls, especially in terms of victimisation, and struggled to respond to these difficulties.

The nature of adolescents' conflict experiences. In line with previous research (e.g., Humphrey \& Symes, 2010), both quantitative and qualitative findings revealed that autistic adolescents were involved in more peer conflict than neurotypical adolescents, particularly as 
victims (Humphrey \& Hebron, 2014). Notably, autistic girls self-reported higher Total Victimhood than all other groups on the RPEQ, a finding that was also present in the interview data. Girls felt this was due to falling short of social expectations (see also Eagly, Wood, \& Diekman, 2000). They reported feeling that their neurotypical peers punish them for not 'getting it' socially, either making them the butt of jokes or excluding them. Many autistic girls talked about instances when peers had suddenly stopped being friendly, often because the girl herself was considered "odd" or "uncool". While girls were more likely to be victims of relational conflict, as expected from neurotypical research (Crick \& Grotpeter, 1995), autistic girls were nevertheless more often victims than their neurotypical peers.

The high levels of relational victimhood amongst autistic girls contrasted with the finding that autistic adolescents were more likely to be involved in overt conflict. This apparent contradiction was driven by high levels of overt conflict amongst boys, which fits with existing research on typical conflict patterns between the genders (Smith, Rose, \& Schwartz-Mette, 2010). It may also be that overt conflict behaviours are easier for autistic adolescents to identify and report (Humphrey \& Lewis, 2008). Considering this, there are (at least) two possible explanations for the elevated levels of relational conflict reported by autistic girls. First, autistic girls might have higher levels of self-insight and social awareness than autistic boys, and are therefore more sensitive to relational aggressions. Second, the degree and nature of conflict experienced by autistic girls may be elevated to such an extent that it has a significantly greater impact on them. Future research should seek to tease apart these potential explanations using more direct tests of social reasoning and interviews with multiple informants.

\section{Gender differences in conflict experiences amongst autistic adolescents.}

The friendships of the autistic girls in this study were qualitatively different to those of autistic boys, as evidenced by both questionnaire and interview data. Autistic girls, like their 
neurotypical counterparts, faced relational conflict, whereas boys faced overt difficulties. The strategies employed to manage conflicts also differed: girls either assumed it was their fault (acknowledging that they often misstep socially), or felt that the conflict was unresolvable, while autistic boys talked about conflict more casually, as something which could be 'got over'. This may be because the conflict they experienced was mainly joking 'taken too far', which is less impactful than the relational aggressions girls faced.

This pattern of findings mirrors research in neurotypical adolescents, which has demonstrated that girls tend to use more compromise and avoidance strategies than boys, who are more likely to use overt anger which dissipates (Owens, Daly, \& Slee, 2005). Young neurotypical women (aged 18-22) are also more effective at conflict resolution than their male counterparts (Brahnam et al., 1982; Black, 2000). Our interview data suggest that this is also true in adolescence, as neurotypical girls seemed to be better at negotiating with their peers, both from their own reports and according to autistic girls helped by neurotypical friends. That autistic girls struggle to do this may contribute to their difficulty resolving peer conflict, as they are not using the strategies which are expected of and available to them. Future intervention efforts should target developing autistic girls' conflict recognition and management skills, such as understanding relational aggression and responding to it effectively. Gender-informed interventions focusing on the different social strategies employed by girls and boys to make and maintain their relationships, as well as those relating to peer difficulties, would also be invaluable in supporting autistic adolescents to successfully engage with their peers, especially in school-based settings.

Camouflaging has been described as the ability to consciously 'mask' the diagnostic features of autism to fit in with neurotypical peers, as "putting on my best normal" (Hull et al., 2017), and is more common in autistic girls/women (Lai et al., 2017). In our study, autistic girls discussed doing this, although, interestingly, to no greater degree than the 
neurotypical girls, who also reported adopting certain behaviours to fit in. In this way, it is possible that camouflaging could just be a 'normal' part of growing up female. It may also be that the late-diagnosed women in the study by Hull et al. (2017) had different experiences of camouflaging, as they grew up in a society which was potentially less accepting of neurodiversity than currently diagnosed adolescent girls.

This study is not without limitations. Repetition between the ADOS-2 'Friends and Marriage' section and some interview questions was inevitable, but this was managed by asking for elaboration on previous answers, rather than simply repeating the enquiry. It was also not possible to contact nominated best-friends to check reciprocity or their views, as in previous work (Calder et al., 2013; Kasari et al., 2011), nor did we ask parents to rate their child's friendships (Bauminger \& Shulman, 2003), which would have provided an additional perspective. Nevertheless, this study focused on young people's views of their own friendship experiences - views that are much under-represented in research (Pellicano, Dinsmore \& Charman, 2014). We also did not ask young people about their experiences of school transition, which may impact on friendships. However, as this was only relevant to a small number of participants $(n=8)$, it is unlikely to have changed the pattern of results. It is also the case that the use of a cognitively-able sample limits the generalisability of the findings, as they may not apply to individuals with co-occurring learning disabilities - although, reassuringly, the results were broadly similar to Sedgewick et al. (2016), who sampled (nonautistic) boys and girls with additional intellectual difficulties.

\section{Conclusion}

Our study clearly shows that autistic boys and girls have very different social experiences - and highlights the importance of gender over diagnostic status in the social experiences of autistic adolescents. Girls are socialised differently from birth (Smith \& Lloyd, 1978), and so gendered environments and activities are likely to play a role in autistic 
girls developing similar friendships to their neurotypical peers. Future longitudinal work should seek to address the development of gender roles in autistic children and adolescents more directly. It would also be beneficial to examine the potential long term mental health consequences of being bullied for autistic girls. Nevertheless, the current findings challenge assumptions in the literature that being autistic 'overrides' being female in some way, as evidenced by the use of majority-male samples to derive results that are applied to both genders (Bauminger et al., 2008; Rowley et al., 2012). Rather, these findings add to a growing body of work supporting the idea that autistic girls (and possibly women) need different strategies and supports to understand and effectively navigate the social expectations placed upon them. 


\section{References}

American Psychiatric Association. (2000). Diagnostic and Statistical Manual of Mental Disorders (4 ${ }^{\text {th }}$ ed., text rev.). Washington, D.C: Author.

American Psychiatric Association. (2013). Diagnostic and Statistical Manual of Mental Disorders: DSM-5. Washington, D.C: American Psychiatric Author.

Antonucci, T. C., \& Akiyama, H. (1987). An examination of sex differences in social support among older men and women. Sex Roles, 17(11), 737-749.

Aukett, R., Ritchie, J., \& Mill, K. (1988). Gender differences in friendship patterns. Sex Roles, 19(1), 57-66.

Baldry, A. C. (2004). The impact of direct and indirect bullying on the mental and physical health of Italian youngsters. Aggressive Behavior, 30(5), 343-355.

Baldwin, S., \& Costley, D. (2015) The experiences and needs of female adults with highfunctioning autism spectrum disorder. Autism, 20(4), 483-495.

Bargiela, S., Steward, R., \& Mandy, W. (2016) The experiences of late-diagnosed women with autism spectrum conditions: an investigation of the female autism phenotype. Journal of Autism and Developmental Disorders, 46(10), 3281-3294.

Baron-Cohen, S. (2002). The extreme male brain theory of autism. Trends in Cognitive Sciences, 6(6), 248-254.

Baron-Cohen, S., \& Wheelwright, S. (2003). The Friendship Questionnaire: An investigation of adults with Asperger syndrome or high-functioning autism, and normal sex differences. Journal of autism and developmental disorders, 33(5), 509-517.

Barbu, S., Cabanes, G., \& Le Maner-Idrissi, G. (2011). Boys and girls on the playground: sex differences in social development are not stable across early childhood. PLoS One, 6(1), e16407. 
Bauminger, N., \& Kasari, C. (2000). Loneliness and friendship in high-functioning children with autism. Child Development, 71(2), 447-456.

Bauminger, N., \& Shulman, C. (2003). The development and maintenance of friendship in highfunctioning children with autism. Autism, 7(1), 81-97.

Bauminger, N., Solomon, M., Aviezer, A., Heung, K., Brown, J., \& Rogers, S. J. (2008).

Friendship in high-functioning children with autism spectrum disorder: Mixed and nonmixed dyads. Journal of Autism and Developmental Disorders, 38(7), 1211-1229.

Bauminger, N., Solomon, M., Aviezer, A., Heung, K., Gazit, L., Brown, J., \& Rogers, S. J.

(2008). Children with autism and their friends: A multidimensional study of friendship in high-functioning autism spectrum disorder. Journal of Abnormal Child Psychology, 36(2), 135-150.

Berkman, L. F., \& Syme, S. L. (1979). Social networks, host resistance, and mortality: a nineyear follow-up study of Alameda County residents. American Journal of Epidemiology, 109(2), 186-204.

Black, K. A. (2000). Gender differences in adolescents' behavior during conflict resolution tasks with best friends. Adolescence, 35(139), 499-512.

Bowie, B. H. (2007). Relational aggression, gender, and the developmental process. Journal of Child and Adolescent Psychiatric Nursing, 20(2), 107-115.

Bowker, J. C. W., Rubin, K. H., Burgess, K. B., Booth-LaForce, C., \& Rose-Krasnor, L. (2006). Behavioral characteristics associated with stable and fluid best friendship patterns in middle childhood. Merrill-Palmer Quarterly (1982-), 671-693.

Braun, V., \& Clarke, V. (2006). Using thematic analysis in psychology. Qualitative Research in Psychology, 3(2), 77-101. 
Brahnam, S. D., Margavio, T. M., Hignite, M. A., Barrier, T. B., \& Chin, J. M. (2005). A genderbased categorization for conflict resolution. Journal of Management Development, 24(3), 197-208.

Bukowski, W. M., Hoza, B., \& Boivin, M. (1994). Measuring friendship quality during pre-and early adolescence: The development and psychometric properties of the Friendship Qualities Scale. Journal of Social and Personal Relationships, 11(3), 471-484.

Calder, L., Hill, V., \& Pellicano, E. (2013). 'Sometimes I want to play by myself': Understanding what friendship means to children with autism in mainstream primary schools. Autism, 17(3), 296-316.

Caldwell, M. A., \& Peplau, L. A. (1982). Sex differences in same-sex friendship. Sex Roles, 8(7), $721-732$.

Chamberlain, B., Kasari, C., \& Rotheram-Fuller, E. (2007). Involvement or isolation? The social networks of children with autism in regular classrooms. Journal of Autism and Developmental Disorders, 37(2), 230-242.

Chevallier, C., Kohls, G., Troiani, V., Brodkin, E. S., \& Schultz, R. T. (2012). The social motivation theory of autism. Trends in Cognitive Sciences, 16(4), 231-239.

Constantino JN, Gruber CP (2012) The Social Responsiveness Scale Manual, Second Edition (SRS-2). Los Angeles, CA: Western Psychological Services.

Crick, N. R., \& Grotpeter, J. K. (1995). Relational aggression, gender, and social-psychological adjustment. Child Development, 66(3), 710-722.

Cridland, E.K., Jones, S.C., Caputi, P., \& Magee, C.A. (2014) Being a girl in a boys' world: investigating the experiences of girls with autism spectrum disorders during adolescence. Journal of Autism and Developmental Disorders, 44(6), 1261-1274. 
Cutting, A. L., \& Dunn, J. (2006). Conversations with siblings and with friends: Links between relationship quality and social understanding. British Journal of Developmental Psychology, 24(1), 73-87.

Dean, M., Harwood, R., \& Kasari, C. (2017) The art of camouflage: gender differences in the social behaviours of girls and boys with autism spectrum disorder. Autism, 21(6), 678689.

De Goede, I. H., Branje, S. J., \& Meeus, W. H. (2009). Developmental changes and gender differences in adolescents' perceptions of friendships. Journal of Adolescence, 32(5), 1105-1123.

Demir, M., \& Urberg, K. A. (2004). Friendship and adjustment among adolescents. Journal of Experimental Child Psychology, 88(1), 68-82.

Dunn, J. (1988). The Beginnings of Social Understanding. Harvard University Press.

Dunn, J., \& Cutting, A. L. (1999). Understanding others, and individual differences in friendship interactions in young children. Social Development, 8(2), 201-219.

Dumont, M., \& Provost, M. A. (1999). Resilience in adolescents: Protective role of social support, coping strategies, self-esteem, and social activities on experience of stress and depression. Journal of Youth and Adolescence, 28(3), 343-363.

Eagly, A. H., Wood, W., \& Diekman, A. B. (2000). Social role theory of sex differences and similarities: A current appraisal. The Developmental Social Psychology of Gender, 123174.

Flanagan, J. C. (1954). The critical incident technique. Psychological Bulletin, 51(4), 327.

Gould, J., \& Ashton-Smith, J. (2011). Missed diagnosis or misdiagnosis? Girls and women on the autism spectrum. Good Autism Practice (GAP), 12(1), 34-41. 
Hayward, S., McVilly, K. R., \& Stokes, M. A. (2016). Challenges for females with high functioning autism in the workplace: a systematic review. Disability and Rehabilitation, 40(3), 249-258.

Head, A. M., McGillivray, J. A., \& Stokes, M. A. (2014). Gender differences in emotionality and sociability in children with autism spectrum disorders. Molecular Autism, 5(1), 19.

Hebron, J., \& Humphrey, N. (2014). Exposure to bullying among students with autism spectrum conditions: A multi-informant analysis of risk and protective factors. Autism, 18(6), 618630.

Hull, L., Petrides, K. V., Allison, C., Smith, P., Baron-Cohen, S., Lai, M. C., \& Mandy, W. (2017). " Putting on My Best Normal": Social Camouflaging in Adults with Autism Spectrum Conditions. Journal of Autism and Developmental Disorders, 47(8), 25192534.

Humphrey, N., \& Lewis, S. (2008). Make me normal' The views and experiences of pupils on the autistic spectrum in mainstream secondary schools. Autism, 12(1), 23-46.

Humphrey, N., \& Symes, W. (2010). Perceptions of social support and experience of bullying among pupils with autistic spectrum disorders in mainstream secondary schools. European Journal of Special Needs Education, 25(1), 77-91.

Hus, V., Gotham, K., \& Lord, C. (2014). Standardizing ADOS domain scores: Separating severity of social affect and restricted and repetitive behaviors. Journal of Autism and Developmental Disorders, 44(10), 2400-2412.

IBM Corp. (2013) IBM SPSS Statistics for Windows, Version 22.0. Armonk, NY: IBM Corp.

Kasari, C., Locke, J., Gulsrud, A., \& Rotheram-Fuller, E. (2011). Social networks and friendships at school: Comparing children with and without ASD. Journal of Autism and Developmental Disorders, 41(5), 533-544. 
Kenny, L., Hattersley, C., Molins, B., Buckley, C., \& Pellicano, E. (2016). Which terms should be used to describe autism? Perspectives from the UK autism community. Autism, 20(4). $442-462$.

Kreiser, N. L., \& White, S. W. (2014). ASD in females: are we overstating the gender difference in diagnosis?. Clinical Child and Family Psychology Review, 17(1), 67-84.

Kuo, M. H., Orsmond, G. I., Cohn, E. S., \& Coster, W. J. (2013). Friendship characteristics and activity patterns of adolescents with an autism spectrum disorder. Autism, 17(4), 481-500.

Lai, M. C., Lombardo, M. V., Ruigok, A. N. V., Chakrabarti, B., Auyeung, B., Szatmari, P., Happé, F., Baron-Cohen, S., \& MRC AIMS Consortium. (2017) Quantifying and exploring camouflaging in men and women with autism. Autism, 21(6), 690-702.

Lai, M. C., Lombardo, M. V., Auyeung, B., Chakrabarti, B., \& Baron-Cohen, S. (2015). Sex/gender differences and autism: setting the scene for future research. Journal of the American Academy of Child \& Adolescent Psychiatry, 54(1), 11-24.

Locke, J., Ishijima, E. H., Kasari, C., \& London, N. (2010). Loneliness, friendship quality and the social networks of adolescents with high-functioning autism in an inclusive school setting. Journal of Research in Special Educational Needs, 10(2), 74-81.

Loomes, R., Hull, L., \& Mandy, W. P. L. (2017). What Is the Male-to-Female Ratio in Autism Spectrum Disorder? A Systematic Review and Meta-Analysis. Journal of the American Academy of Child \& Adolescent Psychiatry, 56(6), 466-474.

Lord, C., Rutter, M., DiLavore, P. C., Risi, S., Gotham, K., \& Bishop, S. (2012). Autism Diagnostic Observation Schedule: ADOS-2. Los Angeles, CA: Western Psychological Services.

McLaughlin, K. A., Hatzenbuehler, M. L., Mennin, D. S., \& Nolen-Hoeksema, S. (2011).

Emotion dysregulation and adolescent psychopathology: A prospective study. Behaviour Research and Therapy, 49(9), 544-554. 
Mitchell, P., Saltmarsh, R., \& Russell, H. (1997). Overly literal interpretations of speech in autism: Understanding that messages arise from minds. Journal of Child Psychology and Psychiatry, 38(6), 685-691.

Office for National Statistics, 2011 Census Data, UK Government: London.

Ortega, R., Elipe, P., Mora-Merchán, J. A., Calmaestra, J., \& Vega, E. (2009). The emotional impact on victims of traditional bullying and cyberbullying: A study of Spanish adolescents. Zeitschrift für Psychologie/Journal of Psychology, 217(4), 197-204.

Owens, L., Daly, A., \& Slee, P. (2005). Sex and age differences in victimisation and conflict resolution among adolescents in a South Australian school. Aggressive Behavior, 31(1), $1-12$.

Pellicano, E., Dinsmore, A., \& Charman, T. (2014). What should autism research focus upon? Community views and priorities from the United Kingdom. Autism, 18(7), 756-770.

Petrina, N., Carter, M., \& Stephenson, J. (2014). The nature of friendship in children with autism spectrum disorders: A systematic review. Research in Autism Spectrum Disorders, 8(2), $111-126$.

Prinstein, M. J., Boergers, J., \& Vernberg, E. M. (2001). Overt and relational aggression in adolescents: Social-psychological adjustment of aggressors and victims. Journal of Clinical Child Psychology, 30(4), 479-491.

Rowley, E., Chandler, S., Baird, G., Simonoff, E., Pickles, A., Loucas, T., \& Charman, T. (2012). The experience of friendship, victimization and bullying in children with an autism spectrum disorder: Associations with child characteristics and school placement. Research in Autism Spectrum Disorders, 6(3), 1126-1134.

Rynkiewicz, A., Schuller, B., Marchi, E., Piana, S., Camurri, A., Lassalle, A., \& Baron-Cohen, S. (2016). An investigation of the 'female camouflage effect' in autism using a computerized ADOS-2 and a test of sex/gender differences. Molecular Autism, 7(1), 10. 
Schroeder, J. H., Cappadocia, M. C., Bebko, J. M., Pepler, D. J., \& Weiss, J. A. (2014). Shedding light on a pervasive problem: A review of research on bullying experiences among children with autism spectrum disorders. Journal of Autism and Developmental Disorders, 44(7), 1520.

Sedgewick, F., Hill, V., Yates, R., Pickering, L., \& Pellicano, E. (2016). Gender differences in the social motivation and friendship experiences of autistic and non-autistic adolescents. Journal of Autism and Developmental Disorders, 46, 1297-1306.

Siegel, R. S., La Greca, A. M., \& Harrison, H. M. (2009). Peer victimization and social anxiety in adolescents: Prospective and reciprocal relationships. Journal of Youth and Adolescence, 38(8), 1096-1109.

Shute, R., Owens, L., \& Slee, P. (2002). "You just stare at them and give them daggers": nonverbal expressions of social aggression in teenage girls. International Journal of Adolescence and Youth, 10(4), 353-372.

Smith, C., \& Lloyd, B. (1978). Maternal behaviour and perceived sex of infant: revisited. Child Development, 49(4), 1263-1265.

Smith, R. L., Rose, A. J., \& Schwartz-Mette, R. A. (2010). Relational and overt aggression in childhood and adolescence: Clarifying mean-level gender differences and associations with peer acceptance. Social Development, 19(2), 243-269.

Steward, R. (2013). The Independent Woman's Handbook for Super Safe Living on the Autistic Spectrum. Jessica Kingsley Publishers.

Travis, L., Sigman, M., \& Ruskin, E. (2001). Links between social understanding and social behavior in verbally able children with autism. Journal of Autism and Developmental Disorders, 31(2), 119-130. 
Underwood, M. K. (2004) Glares of contempt, eye rolls of disgust and turning away to exclude: non-verbal forms of social aggression among girls. Feminism \& Psychology, 14(3), 371375.

Vine Foggo, R. S., \& Webster, A. A. (2017). Understanding the social experiences of adolescent females on the autism spectrum. Research in Autism Spectrum Disorders, 35, 74-85.

Webster, A.A., \& Garvis, S. (2016). The importance of critical life moments: an explorative study of successful women with autism spectrum disorder. Autism, 21(6), 670-677.

Wechsler D. (2011). Wechsler Abbreviated Scale of Intelligence-Second Edition (WASI-II). San Antonio, TX: NCS Pearson. 
Appendix A. Interview schedule used with autistic and neurotypical adolescents, with main questions and prompts.

$\underline{\text { Key Question }}$

Can you tell me a bit about your friends?

What does being a friend mean to you?

Can you tell me some good things and some difficult things about your friends?

What about romantic relationships?

Can you tell me about a time when something bad happened with your friends, or when your friends did something you didn't like?

Can you tell me about a time when you had a lot of fun with your friends, or when something good happened with them? (same prompt questions)

Is there anything else you think it would be interesting for me to know about your friendships or how you get on with people?

\section{Question Prompts}

Do you have many friends?

Where do you see them? How often?

What do you do with your friends?

Do you use the internet to keep in touch with friends?

Are you happy with the friends you have?

How do you know when someone is your friend? What is a good friend?

Are there some friends who are more important than others? Why?

Have you ever had not-so-good friends, or people who pretended to be your friend?

Do your friends help you?

Have you ever been annoyed by your friends or annoyed them? Do you argue with your friends?

How do you try to sort it out when you argue with your friends?

Are you dating? If not: Would you like to in the future?

Are any of your friends dating?

Why do you think people date at school?

How is someone you date different to a friend?

Do you have to do different things to stay dating than to stay friends? Are the arguments different?

Why do you think it happened?

What did you do?

What happened afterwards? Did you sort it out? How?

How did you feel?

Did people remember? Did it change your friends?

Would you do anything different if it happened again? 